\title{
Concentração espermática e tempo de incubação na fecundação in vitro usando-se sêmen de touros da raça Guzerá
}

[Sperm concentration and incubation period on in vitro fecundation using sperm of Guzera bulls]

\author{
L.P.B. Dias $^{1}$, W.F. $\operatorname{Sa}^{2}$. L.S.A. Camargo $^{2}$, A.A. Ramos $^{3}$, A.M. Ferreira ${ }^{2}$, \\ J.H.M. Viana ${ }^{2}$, L.A.G. Nogueira ${ }^{1}$ \\ ${ }^{1}$ Universidade Federal Fluminense - Niterói, RJ \\ ${ }^{2}$ Embrapa Gado de Leite \\ Rua Eugênio do Nascimento, 610 \\ 36038-330 - Juiz de Fora, MG \\ ${ }^{3}$ EPAMIG - Juiz de Fora, MG
}

\begin{abstract}
RESUMO
Estudou-se o efeito da concentração espermática e período de incubação e da interação dessas características sobre a fecundação in vitro (FIV) usando-se sêmen de touros Guzerá. Oócitos ( $\mathrm{n}=1146)$ maturados in vitro foram divididos em tratamentos objetivando a FIV, em esquema fatorial $3 \times 2 \times 2$ (três touros - A, B e C, duas concentrações espermáticas - 2 e $4 \times 10^{6}$ espermatozóides $/ \mathrm{ml}$ e dois tempos de incubação 12 e 18 horas). Utilizaram-se espermatozóides viáveis obtidos por swin-up. A FIV foi realizada em meio fert-talp com heparina, em incubadora com $5 \%$ de $\mathrm{CO}_{2}$ e $95 \%$ de umidade, a $38,5^{\circ} \mathrm{C}$. Após incubação, $50 \%$ dos oócitos foram fixados e corados para determinação das taxas de penetração, fecundação monoespermática e poliespermia. $\mathrm{O}$ restante foi co-cultivado com células da granulosa em meio CR2aa por oito dias, avaliando-se a taxa de clivagem e a produção de blastocisto. Houve maior taxa de penetração $(\mathrm{P}<0,05)$ na concentração de $4 \times 10^{6}$ espermatozóides/ml por 18 horas $(64 \%)$, e não se observou diferença $(\mathrm{P}>0,05)$ entre os demais tratamentos. A taxa de poliespermia foi maior $(\mathrm{P}<0,05)$ na concentração espermática de $4 \times 10^{6}$, independente do tempo de incubação. Na concentração espermática mais alta, a taxa de poliespermia foi maior no tempo de incubação de 18 horas $(\mathrm{P}<0,05)$. O touro $\mathrm{A}$ apresentou menor $(\mathrm{P}<0,05)$ taxa de poliespermia em relação aos demais. Ainda, no touro $\mathrm{A}$ a taxa de clivagem foi maior $(\mathrm{P}<0,05)$ que no touro $\mathrm{B}$, enquanto o $\mathrm{C}$ mostrou-se semelhante tanto ao A quanto ao B. O tempo de incubação, a concentração espermática e a interação das variáveis influenciaram as taxas de penetração e poliespermia, sem interferir na taxa de fecundação monoespermática e na produção de blastocistos.
\end{abstract}

Palavras-chave: bovino, Guzerá, fecundação in vitro, concentração espermática, tempo de incubação

\section{ABSTRACT}

The effects of sperm concentration, incubation period and their interaction on in vitro fertilization (IVF) using sperm of Guzera bulls were evaluated. In vitro matured oocytes $(n=1146)$ were allotted to IVF treatments in a factorial scheme $3 \times 2 \times 2$ - three bulls (A, B and C), two sperm concentrations (2 and $4 \times 10^{6}$ spermatozoa/ml) and two incubation periods (12 and $\left.18 \mathrm{~h}\right)$. Viable spermatozoa were obtained by swim-up. The IVF was performed using in Fert-Talp medium with heparin, on incubator with $5 \% \mathrm{CO}_{2}$ and $95 \%$ humidity, at $38.5^{\circ} \mathrm{C}$. After the incubation, $50 \%$ of oocytes were fixed and stained to determine penetration, monospermic fecundation and polyspermy rates. The remainder was co-cultured with granulosa cells in CR2 medium for eight days to evaluate cleavage and embryo production rates. The penetration rate was higher $(P<0.05)$ for sperm concentration of $4 \times 10^{6}$ spermatozoa/ml incubated for 18

Recebido em 15 de março de 2005

Aceito em 28 de novembro de 2005

*Autor para correspondência (corresponding author)

E-mail: wandefsa@cnpgl.embrapa.br 
hours (64\%), and no differences ( $P>0.05)$ among remainder treatments were observed. The polyspermic rate $(P<0.05)$ was higher for higher sperm concentration and incubation period. Bull $A$ showed the lowest $(P<0.05)$ polyspermy rate. Bulls $A$ and $C$ showed higher $(P<0.05)$ cleavage than bull $B$. Incubation period, sperm concentration, and interaction of these two factors influenced penetration and polyspermy rates, without any effect on monospermic fecundation rates and embryos production.

Keywords: beef cattle, Guzera, in vitro fertilization, incubation period, sperm concentration

\section{INTRODUÇÃO}

Para o sucesso de um sistema de produção in vitro de embriões (PIVE), é necessário um processo de fecundação in vitro (FIV) eficiente, capaz de proporcionar alta taxa de penetração, reduzindo o número de fecundações anormais. A poliespermia tem sido a alteração mais freqüente na FIV (Long et al., 1994; Ramos et al., 2000; Camargo et al., 2001). Outra alteração possível é a diminuição do potencial de desenvolvimento do oócito provocado por enzimas hidrolíticas e radicais livres liberados pelos espermatozóides (Rehman et al., 1994). Concentração espermática e período de incubação inadequados podem ocasionar aumento na taxa de poliespermia e maior tempo de contato do oócito com substâncias tóxicas liberadas pelos espermatozóides, prejudicando o desenvolvimento embrionário posterior (Long et al., 1994; Camargo et al., 2001).

Sabendo-se das diferenças entre as raças taurinas e zebuínas quanto à fertilidade em sistemas de PIVE (Brackett e Keskintepe, 1996), torna-se desaconselhável utilizar resultados obtidos em animais europeus para comparação com animais de raças zebuínas. Vários estudos procuraram estabelecer o tempo de incubação oócito-espermatozóide e a concentração mínima de sêmen ideais para que ocorra maior número de fecundações monoespermáticas e, conseqüentemente, maior produção de embriões, entretanto pouca informação existe a respeito das raças zebuínas (Watanabe et al., 1996; Ramos et al., 2000; Camargo et al., 2001), e quase nenhuma na raça Guzerá (Camargo et al., 2000). Devido à importância dessa raça como animal puro ou em cruzamentos para produção de mestiços, há a necessidade do estudo de protocolos de PIVE para animais Guzerá, visando contribuir para o progresso genético da raça.

O objetivo deste trabalho foi testar diferentes concentrações espermáticas e tempos de incubação do sêmen de touros da raça Guzerá com oócitos oriundos de matadouros, na presença de heparina, para verificar qual o protocolo com maior eficiência sobre a taxa de fecundação, clivagem e obtenção de embriões até o estádio de blastocisto.

\section{MATERIAL E MÉTODOS}

Os oócitos utilizados foram aspirados de ovários de fêmeas mestiças provenientes de matadouro. Os ovários foram transportados em garrafas térmicas, contendo solução fisiológica $(0,9 \%$ $\mathrm{NaCl}$ e $0,1 \mathrm{~g} / 1$ de sulfato de estreptomicina), à temperatura entre 30 e $34^{\circ} \mathrm{C}$, por um período de até três horas após a coleta.

Os folículos que apresentavam diâmetro superior a $3 \mathrm{~mm}$ foram puncionados, e o conteúdo depositado em cálice cônico contendo Talp Hepes (Baviester et al., 1983), a aproximadamente $37^{\circ} \mathrm{C}$. Após a decantação, os oócitos que apresentavam células do cumulus oophorus compacto com no mínimo três camadas e citoplasma homogêneo foram selecionados.

Um total de 1146 oócitos foram maturados in vitro em placas de Petri contendo $3 \mathrm{ml}$ de meio TCM199 acrescido de $10 \%$ de soro da vaca em cio e $20 \mu \mathrm{g} / \mathrm{ml}$ de FSH, conforme Costa (1994). A maturação foi realizada por 24 horas em estufa incubadora à temperatura de $38,5^{\circ} \mathrm{C}$ e $95 \%$ de umidade, com 5\% de $\mathrm{CO}_{2} \mathrm{em}$ ar atmosférico.

Os oócitos maturados foram submetidos à nova seleção, sendo descartados aqueles que não haviam expandido o cumulus oophorus e os que haviam degenerado; o restante foi levado a fecundação in vitro. $\mathrm{O}$ delineamento experimental foi inteiramente ao acaso, com cinco repetições. Os tratamentos consistiram de um fatorial $3 \times 2 \times 2$ ( touro, concentração espermática, tempo de incubação). Foram utilizados os touros A, B e C da raça Guzerá, 
as concentrações espermáticas de $2 \times 10^{6}$ espermatozóides $/ \mathrm{ml}$ e $4 \times 10^{6}$ espermatozóides $/ \mathrm{ml}$ e os tempos de incubação de 12 e 18 horas.

O sêmen foi descongelado em banho-maria a $37^{\circ} \mathrm{C}$ por 30 segundos e avaliado quanto ao vigor e motilidade. Espermatozóides viáveis foram obtidos pela técnica do swim-up (Parrish et al., 1985) e distribuídos aleatoriamente pelos tratamentos.

A fecundação foi realizada em gotas de $100 \mu \mathrm{l}$ de meio Fert-Talp acrescido de heparina $(100 \mu \mathrm{g} / \mathrm{ml})$, cobertas com óleo mineral e logo em seguida colocadas em estufa de $\mathrm{CO}_{2}$ nas mesmas condições da maturação.

Após o período de fecundação, $50 \%$ dos possíveis zigotos foram fixados em lâminas para avaliação da taxa de fecundação, preparadas segundo Costa (1994). Avaliou-se a fecundação pela presença dos pronúcleos feminino e masculino ou de dois conjuntos cromossômicos com a presença da cauda do espermatozóide. Foram considerados poliespermáticos zigotos que apresentavam mais de dois pronúcleos, e como não fecundados os com ausência de pronúcleos (Costa, 1994; Xu e Greve, 1988). O restante das estruturas foi cultivado em gotas com $100 \mu \mathrm{l}$ de meio quimicamente definido (CR2) em co-cultivo com células da granulosa adicionado com $3 \mathrm{~g} / \mathrm{l}$ albumina sérica bovina $\mathrm{e}$ $10 \%$ de soro de vaca em cio, em estufa com $5 \%$ de $\mathrm{CO}_{2}, 95 \%$ de ar atmosférico, $95 \%$ de umidade a $38,5^{\circ} \mathrm{C}$. O meio de cultivo foi renovado a cada 48 horas. A taxa de clivagem foi avaliada com 72 horas e a de blastocisto oito dias pósinseminação.

A avaliação estatística baseou-se na análise de variância, utilizando o Statistical Analisys System (User's..., 1985) em modelo que incluiu os efeitos de touro, o tempo de incubação, a concentração espermática e as interações entre esses fatores. As médias das taxas de fecundação mono e poliespermáticas e de clivagem e a produção de blastocistos foram corrigidas pelo método dos quadrados mínimos, e utilizou-se o teste Student Newman Kuels para comparação entre médias.

\section{RESULTADOS E DISCUSSÃO}

Não se observou aumento da taxa de fecundação monoespermática entre as concentrações espermáticas e os períodos de incubação avaliados $(\mathrm{P}>0,05)$, o que refletiu em taxas de clivagem e de blastocistos semelhantes $(\mathrm{P}>0,05)$ (Tab. 1). As Tab. 2 e 3 mostram os resultados da interação entre o tempo de incubação e a concentração espermática, e nelas observa-se que o aumento da concentração espermática concomitante com a elevação do tempo de incubação resultou em maior taxa de penetração espermática e poliespermia $(\mathrm{P}<0,05)$, sem no entanto afetar as demais características. Há relatos de que o aumento no tempo de incubação promove aumento na penetração espermática. Segundo Tajik e Niwa (1998), o aumento ocorre proporcionalmente ao tempo entre 16 e 22 horas de exposição dos oócitos aos espermastozóides. Resultados semelhantes, observados por Ramos et al. (2000) na raça Gir, mostram que o ajuste entre concentração espermática e tempo de incubação durante a fecundação in vitro pode contribuir para a redução da taxa de poliespermia. Camargo et al. (2002), ao avaliarem sêmen de touros da raça Gir, também observaram aumento da poliespermia na concentração espermática de $4 \times 10^{6}$ células $/ \mathrm{ml}$. O resultado deste trabalho, quando comparado com os da literatura citada, sugere que o sêmen da raça Guzerá comporta-se de maneira semelhante ao da raça Gir, durante a fecundação in vitro.

Tabela 1. Taxas de fecundação, de clivagem e de produção de blastocistos (\%), segundo o tempo de incubação e a concentração espermática $(\overline{\mathrm{X}} \pm \mathrm{EP})$ do sêmen de três touros da raça Guzerá

\begin{tabular}{lccccc}
\hline Tempo de incubação & $\mathrm{n}^{1}$ & Fecundação monespermática & $\mathrm{n}^{2}$ & Clivagem & Blastocisto \\
\hline 12 & 285 & $44,05 \pm 1,72^{\mathrm{a}}$ & 593 & $47,86 \pm 4,14^{\mathrm{a}}$ & $17,40 \pm 2,41^{\mathrm{a}}$ \\
18 & 332 & $46,60 \pm 1,86^{\mathrm{a}}$ & 553 & $52,96 \pm 4,46^{\mathrm{a}}$ & $19,23 \pm 2,41^{\mathrm{a}}$ \\
Concentração espermática & & & & & \\
$2 \times 10^{6}$ sptz/ml & 291 & $45,84 \pm 1,96^{\mathrm{a}}$ & 549 & $47,52 \pm 3,61^{\mathrm{a}}$ & $18,28 \pm 2,64^{\mathrm{a}}$ \\
$4 \times 10^{6} \mathrm{sptz} / \mathrm{ml}$ & 326 & $44,81 \pm 2,10^{\mathrm{a}}$ & 597 & $52,41 \pm 4,90^{\mathrm{a}}$ & $18,36 \pm 2,18^{\mathrm{a}}$ \\
\hline
\end{tabular}

Letras distintas na coluna indicam diferenças entre os valores ( $\mathrm{SNK} ; \mathrm{P}<0,05)$.

${ }^{1}$ Total de oócitos fixados em lâminas para a avaliação da fecundação monoespermática.

${ }^{2}$ Total de oócitos mantidos em cultivo para avaliação da clivagem e produção de blastocistos. 
Tabela 2. Interação tempo de incubação versus concentração espermática sobre a taxa de penetração $(\overline{\mathrm{X}} \pm \mathrm{EP})$ do sêmen de três touros da raça Guzerá

\begin{tabular}{lcc}
\hline Concentração & \multicolumn{2}{c}{ Tempo de incubação } \\
\cline { 2 - 3 } espermática & \multicolumn{1}{c}{12} & 18 \\
\hline $2,0 \times 10^{6} \mathrm{sptz} / \mathrm{ml}$ & $49,25 \pm 2,25 \mathrm{aA}$ & $52,41 \pm 2,16 \mathrm{aB}$ \\
$4,0 \times 10^{6} \mathrm{sptz} / \mathrm{ml}$ & $52,63 \pm 2,61 \mathrm{bA}$ & $65,14 \pm 2,39 \mathrm{aA}$ \\
\hline Na linha a $>\mathrm{b} ;$ na coluna $\mathrm{A}>\mathrm{B}(\mathrm{SNK} ; \mathrm{P}<0,05)$.
\end{tabular}

Tabela 3. Interação tempo de incubação versus concentração espermática sobre a taxa de poliespermia $(\overline{\mathrm{X}} \pm \mathrm{EP})$ do sêmen de três touros Guzerá

\begin{tabular}{lcc}
\hline Concentração & \multicolumn{2}{c}{ Tempo de incubação } \\
\cline { 2 - 3 } espermática & 12 & 18 \\
\hline $2,0 \times 10^{6} \mathrm{sptz} / \mathrm{ml}$ & $1,70 \pm 0,64 \mathrm{aB}$ & $3,06 \pm 0,98 \mathrm{aB}$ \\
$4,0 \times 10^{6} \mathrm{sptz} / \mathrm{ml}$ & $4,93 \pm 0,44 \mathrm{bA}$ & $11,18 \pm 1,52 \mathrm{aA}$ \\
\hline $\mathrm{Na}$ linha $\mathrm{a}>\mathrm{b} ;$ na coluna $\mathrm{A}>\mathrm{B}(\mathrm{SNK} ; \mathrm{P}<0,05)$.
\end{tabular}

Apesar de alguns autores comentarem que concentrações espermáticas elevadas também aumentam a taxa de monospermia (Rehman et al., 1994; Saeki et al., 1995), tal fato não foi observado neste trabalho. A manutenção de taxas de monospermia semelhantes entre concentrações e a interação concentração versus tempo pode ser atribuída ao aumento da penetração espermática acompanhado pelo aumento da poliespermia, evitando o aumento da monospermia, semelhante ao observado por Long et al. (1994).

A maior taxa de poliespermia $(\mathrm{P}<0,05)$ observada na interação maior concentração versus tempo de incubação (Tab. 3) pode ser atribuída a alterações na integridade dos oócitos, conseqüentes do aumento do tempo de incubação. Essas alterações podem ter causado um decréscimo na efetividade do exudato dos grânulos corticais e/ou alteração da zona pelúcida, e de sua resposta ao exudato dos grânulos corticais, o que levaria à diminuição na eficiência da reação cortical e, conseqüentemente, do bloqueio da poliespermia (Long et al., 1994). Em alta concentração espermática, possivelmente, existe alto teor de enzimas hidrolíticas no meio de fecundação, liberadas pela presença de espermatozóides a mais do que o necessário, o que também pode provocar poliespermia, uma vez que essas enzimas em excesso podem facilitar a penetração de mais de um espermatozóide (Ramos et al., 2000).
A manutenção de baixa taxa de poliespermia é importante durante a fecundação, pois leva à produção de embriões triploídes, os quais normalmente não alcançam o estádio de blastocisto.

A ausência de efeito da concentração espermática $(\mathrm{P}>0,05)$ na fecundação in vitro sobre a taxa de clivagem (Tab. 1) também foi observada por Camargo et al. (2000). Esses autores não verificaram aumento na taxa de clivagem com concentrações entre 1 e $4 \times 10^{6}$ espermatozóides/ml, contudo, na concentração de $0,5 \times 10^{6}$ células $/ \mathrm{ml}$ a clivagem foi menor. Esses resultados sugerem que concentrações entre 1 e $2 \times 10^{6}$ espermatozóides/ml são mais adequadas para a FIV com sêmen de touros da raça Guzerá, mantendo, assim, a taxa de clivagem sem aumentar a taxa de poliespermia.

A manipulação do tempo de incubação isoladamente não parece ser um fator limitante ao sucesso da fecundação in vitro com sêmen de touros Guzerá, uma vez que não se observou diferença $(\mathrm{P}>0,05)$ nas variáveis taxas de clivagem e de blastocisto com 12 e 18 horas de incubação oócito:espermatozóides. Resultados semelhantes foram observados por Dode et al. (1998), Ramos et al. (2000) e Camargo et al. (2002), todos utilizando sêmen de touros zebu. Considerando-se que as primeiras penetrações espermáticas ocorrem próximo de $6 \mathrm{~h}$ após o início de cultivo de fecundação in vitro $(\mathrm{Xu}$ e Greve, 1988), 12 horas de cultivo parecem ser suficientes para se atingir uma taxa de clivagem e produção de blastocistos otimizada, concordando com outros autores (Ward et al., 2002).

A interação concentração espermática versus tempo de incubação não interferiu nas taxas de clivagem e de blastocistos $(\mathrm{P}>0,05)$, semelhantemente ao encontrado por Watanabe et al. (1996) e Ramos et al. (2000), que utilizaram maiores concentrações espermáticas na fecundação in vitro em touros Nelore e Gir, respectivamente. Entretanto, Camargo et al. (2002) observaram aumento na taxa de clivagem ao utilizarem maior concentração associada a elevado tempo de incubação. Diferenças entre trabalhos podem ser atribuídas às condições de cultivo durante a fecundação in vitro, induzindo a partenogênese (Martini et al., 2000) e a poliespermia (Chian et al., 1992). Embriões 
partenogenéticos e oriundos de fecundação poliespermática dividem-se, mas raramente atingem estádio de blastocistos (Gordon, 1994), provocando aumento da clivagem.

Ao comparar os resultados dos touros utilizados neste experimento, verificaram-se diferenças quanto às taxas de poliespermia e de clivagem $(\mathrm{P}<0,05)$, sem alteração nas taxas de penetração, fecundação monospermática e de blastocistos (Tab. 4). Diferenças de fertilidade entre touros têm sido identificadas, tanto a campo como em testes in vitro (Marquant-Le Guienne et al., 1990; Rodriguez-Martinez e Larsson, 1998; Brahmkshtri et al., 1999). Sêmen de touros com características morfológicas semelhantes pode apresentar diferentes resultados na fecundação in vitro, por apresentar diferente habilidade em capacitar durante o cultivo in vitro. Isso, provavelmente, é atribuído à presença ou não de proteínas associadas à fertilidade (Bellin et al., 1998; McCauley et al., 2001), ou à diferença de velocidade dos espermatozóides em fertilizar, proporcionando embriões de melhor qualidade para os touros cuja fecundação inicia-se mais cedo (Ward et al., 2002). Para touros da raça Gir, verificou-se que a elevação da concentração espermática diminuiu a diferença entre touros quanto às taxas de clivagem e de blastocistos (Camargo et al., 2002). Essas informações sugerem que as diferenças na fecundação in vitro entre touros podem ser minimizadas, manipulando-se a concentração de agentes indutores da capacitação e a concentração espermática.

Tabela 4. Taxas de penetração, fecundação, poliespermia, clivagem e produção de blastocistos $(\overline{\mathrm{X}} \pm \mathrm{EP})$, segundo o touro, na raça Guzerá

\begin{tabular}{lccccccc}
\hline $\begin{array}{l}\text { Concentração } \\
\text { espermática }\end{array}$ & $\mathrm{n}^{1}$ & Penetração & $\begin{array}{c}\text { Fecundação } \\
\text { monespermática }\end{array}$ & Poliespermia & $\mathrm{n}^{2}$ & Clivagem & Blastocisto \\
\hline $\mathrm{A}$ & 224 & $52,63 \pm 2,76 \mathrm{a}$ & $47,64 \pm 1,91 \mathrm{a}$ & $3,13 \pm 0,83 \mathrm{~b}$ & 399 & $59,08 \pm 7,20 \mathrm{a}$ & $18,00 \pm 2,91 \mathrm{a}$ \\
$\mathrm{B}$ & 163 & $57,56 \pm 2,94 \mathrm{a}$ & $45,02 \pm 2,86 \mathrm{a}$ & $6,13 \pm 1,30 \mathrm{a}$ & 317 & $40,76 \pm 2,85 \mathrm{~b}$ & $15,48 \pm 2,51 \mathrm{a}$ \\
$\mathrm{C}$ & 252 & $54,39 \pm 1,59 \mathrm{a}$ & $43,30 \pm 1,63 \mathrm{a}$ & $6,39 \pm 1,39 \mathrm{a}$ & 430 & $50,05 \pm 3,90 \mathrm{ab}$ & $21,47 \pm 3,31 \mathrm{a}$ \\
\hline
\end{tabular}

Letras distintas na coluna indicam diferenças entre os valores ( $\mathrm{SNK} ; \mathrm{P}<0,05$ ).

${ }^{1}$ Total de oócitos fixados em lâminas para a avaliação da penetração, fecundação monoespermática e poliespermia.

${ }^{2}$ Total de oócitos mantidos em cultivo para avaliação da clivagem e produção de blastocistos.

\section{CONCLUSÕES}

O tempo de incubação e a concentração espermática não têm efeito sobre a fecundação monoespermática e a produção de blastocisto em animais da raça Guzerá. Há necessidade da avaliação do sêmen antes de ser utilizado na FIV, em razão da diferença entre touros quanto às taxas de poliespermia e clivagem.

\section{REFERÊNCIAS BIBLIOGRÁFICAS}

BAVIESTER, B.D.; LEIBFRIEND, M.L.; LIEBERMAN, G. Development of preimplantation embryos of the Golden hamster in a defined culture medium. Biol. Reprod., v.28, p.235-243, 1983.

BELLIN, M.E.; OYARZO, J.N.; HAWKINS, H.E. et al. Fertility-associated antigen on bull sperm indicates fertility potential. J. Anim Sci., v.76, p.2032-2039, 1998.
BRACKETT, B.W.; KESKINTEPE, L. Defined sperm treatments and insemination conditions enable improved bovine embryos production in vitro. Theriogenology, v.45, p.259, 1996.

BRAHMKSHTRI, B.P.; EDWIN, M.J.; JOHN, M.C. et al. Relative efficacy of conventional sperm parameters and sperm penetration bioassay to assess bull fertility in vitro. Anim. Reprod. Sci., v.54, p.159-168, 1999.

CAMARGO, L.S.A.; RAMOS, A.A.; SÁ, W.F. et al. Fecundação in vitro com sêmen de touros da raça Gir. Cad. Téc. Vet. Zootec., n. 35, p.8996, 2001.

CAMARGO, L.S.A.; SÁ, W.F.; FERREIRA, A.M. et al. Concentração espermática na fecundação in vitro, com sêmen de touros Guzerá. Arq. Bras. Med. Vet. Zootec., v.52, p.5964, 2000.

CAMARGO, L.S.A.; SÁ, W.F.; FERREIRA, A.M. et al. Efeito de concentração espermática e período de incubação oócito-espermatozóide na 
fecundação in vitro em bovinos da raça Gir. Pesq. Agropec. Bras., v.37, p.709-715, 2002.

CHIAN, R. C.; NAKAHARA, H.; KIWA, K. et al. Fertilization and early cleavage in vitro of ageing bovine oocytes after maturation in culture. Theriogenology, v.37, p.665-672, 1992.

COSTA, E.P. Aspectos morfológicos (citológicos e ultra-estruturais) e desenvolvimento de ovócitos bovinos in vitro. 1994. 155f. Tese (Doutorado) - Escola de Veterinária, Universidade Federal de Minas Gerais, Belo Horizonte.

DODE, M.A.N.; RODOVALHO, N.C.; UENO, V.G. et al. O tempo de incubação de ovócitos e espermatozóides bovinos na taxa de penetração e clivagem. Arq. Fac. Vet. UFRGS, v.26, supl., p.254, 1998.

GORDON, I. Laboratory production of cattle embryos. CAB International. London: Cambridge University, 1994. 640p

LONG, C.R.; DMIANI, P.; PINTO-CORREIA, R.A et al.. Morphology and subsequent development in culture of bovine oocytes matured in vitro under various conditions of fertilization. J. Reprod. Fertil., v.102, p.361-369, 1994.

MARQUANT-LE GUIENNE, B.; HUMBLOT, P.; THIBIER, M. et al. Evaluation of bull semen fertility by homologous in vitro fertilization tests. Reprod. Nutr. Dev., v.30, p.259-266, 1990.

MARTINI, A.C.; FIOL, D.E.; CUNEO, M. et al. In vitro parthenogenesis of mouse oocytes under several experimental conditions. Zygote, v.8, p.45-49, 2000.

MCCAULEY, T.C.; ZHANG, H.M.; BELLIN, M.E. et al. Identification of a heparin-binding protein in bovine seminal fluid as tissue inhibitor of metalloproteinases-2. Mol. Reprod. Dev., v.58, p.336-341, 2001.

PARRISH， J.J.; SUSKO-PARRISH， J.L.; FIRST, N.L. Effects of heparin and chondroitinn sulfate on the acrosome reaction and fertility of bovine sperm in vitro. Theriogenology, v.24, p.537-549, 1985.

RAMOS, A.A.; CAMARGO, L.S.A.; SÁ, W.F. et al. Fecundação in vitro com sêmen de bovinos da raça Gir. Arq. Bras. Med. Vet. Zootec., v.52, p.360-365, 2000.

REHMAN, N.; COLLINS, A.R.; DUH, T.K. et al. Development of in vitro matured and fertilized bovine oocytes co-cultured with buffalo rat liver cells. Theriogenology, v.41, p.1453-1462, 1994.

RODRIGUEZ-MARTINEZ, H.; LARSSON, B. Assessment of sperm fertilizing ability in farm animals. Acta Agric. Scand., v.29, p.12-18, 1998.

SAEKI, K.; NAGAO, Y.; HOSHI, M. et al. Effects of heparin, sperm concentration and bull variation on in vitro fertilization of bovine oocytes in protein-free medium. Theriogenology, v.44, p.859-869, 1995.

TAJIK, P.; NIWA, K. Effects of caffeine and/or heparin in chemically defined medium with or without glucose on in vitro penetration of bovine oocytes and their subsequent development. Theriogenology, v.49, p.771-777, 1998.

USER'S guide: statistics. Cary: SAS Institute, 1985.

WARD, F.; BRIAN, E.; RIZOS, D. et al. Optimization of in vitro bovine embryo production: effect of duration of maturation, length of gamete co-incubation, sperm concentration and sire. Theriogenology, v.57, p.2105-2117, 2002.

WATANABE, Y.F.; AZAMBUJA, R.M.; PERIPATO, A.C. et al. Efeito de touros na produção in vitro de embriões com diferentes concentrações de heparina e de espermatozóides. Arq. Fac. Vet. UFRGS, v.24, supl., p.250, 1996.

XU, K.P.; GREVE, T. A detailed analysis of early events during in-vitro fertilization of bovine follicular oocytes. J. Reprod. Fertil., v.82, p.127-134, 1988. 